\title{
Stakeholder Governance Paradigm in Response to the COVID-19 Pandemic
}

\author{
Zabihollah Rezaee ${ }^{1, *} \&$ Nick J. Rezaee ${ }^{2}$ \\ ${ }^{1}$ Thompson-Hill Chair of Excellence \& Professor of Accountancy, Fogelman College of \\ Business and Economics, The University of Memphis, Memphis, TN 38152-3120, USA \\ ${ }^{2}$ Department of Biological Engineering, Computational Biologist, California Institute of \\ Technology, Pasadena, CA 91125, USA \\ *Corresponding author: Thompson-Hill Chair of Excellence \& Professor of Accountancy, \\ Fogelman College of Business and Economics, 300 Fogelman College Administration \\ Building, The University of Memphis, Memphis, TN 38152-3120, USA. Tel: \\ 1-901-678-4652. E-mail: zrezaee@memphis.edu
}

Received: October 7, 2020 Accepted: October 27, 2020 Published: November 18, 2020

doi: 10.5296/jcgr.v4i1.18314 URL: https://doi.org/10.5296/jcgr.v4i1.18314

\begin{abstract}
The COVID-19 pandemic has tremendous implications for people and organizations. It has influenced organization behavior and may trigger a paradigm shift regarding the way business organizations consider governance under the new normal. This study conducts a synthesis of the literature and provides an insight into the COVID-19 crisis and its impacts on organization behavior and corporate governance norms and measures. Stakeholder governance of protecting interests of all stakeholders presented in this paper is appropriate in addressing challenges brought on by the COVID-19 pandemic that affect organization behavior. These challenges and related changes will affect all aspects of business organizations from the oversight function by the board of directors to the managerial function by executives. Stakeholder governance is driven from the stakeholder primacy concept with focus on creating and protecting shared value for all stakeholders. Stewardship theory can predict changes that business organizations will make in modifying their stakeholder governance in the face of such an exogenous shock caused by the pandemic. Propositions are advanced and suggestions are provided for policy, practical, education, and research implications.
\end{abstract}

Keywords: corporate governance, stakeholder governance, the covid-19 pandemic, shareholder primacy, stakeholder primacy, stewardship theory, profit-with-purpose

JEL Classification: G34, M41. D84, E44, F30, G17, Q56

Conflicts of Interest: The author declares no conflict of interest 


\section{Introduction}

The COVID-19 pandemic has created devastating human, social, environmental, and economic consequences worldwide and has been an exogenous shock in the economy that has influenced organization behavior. This study conducts a synthesis of the exiting literature in identifying the gap in the existing literature regarding the modification of corporate governance in response to the pandemic and provides an insight into the COVID-19 pandemic and its impacts on organization governance norms and measures. The pandemic has changed the everyday life of people and new realities of economic shutdowns, individual lockdowns, business closures, and social distancing have created unique challenges and changes in behavior for global business organizations. Daily activities and business practices have significantly adjusted to the "new normal" in response to the pandemic, with new business office designs, social distancing, remote working, virtual meetings, business continuity, and transformation and changes in corporate governance functions. Brammer, Branicki and Linnenluecke (2020), using theory of socialization, examine how the COVID-19 pandemic affect the role of business in society and conclude that the pandemic posed challenges that caused regulatory response, organization behavior and societal backlash. The pandemic has significant implications for people and organizations around the world, and it may trigger a paradigm shift in corporate governance with a new focus on stakeholder governance in protecting interests of all stakeholders. Stakeholder governance is a process of managing and running a corporation to serve interests of all stakeholders including shareholders, employees, suppliers, customers, communities, society, and the environment and thus could be a better solution to corporate accountability, economic performance, and prosperity in response to the COVID-19 pandemic.

The stakeholder governance concept with the focus on stakeholders has recently been extensively yet inconclusively debated in the governance and accounting literature. Proponents support stakeholder capitalism and stakeholder governance that intends to benefit all stakeholders (Meyer, 2019). Opponents argue that stakeholder governance does not benefit stakeholders while imposes additional costs on shareholders and society (Bebchuk and Tallarita, 2020). However, the World Economic Forum (WEF, 2020a) supports the concept of stakeholder governance in the context of stakeholder capitalism and has developed the stakeholder governance principles to protect interests of shareholders, employees, customers, suppliers, governments, and society as part of its COVID Action Platform (WEF, 2020b). Kaufman and Englander (2005) propose a team production model of corporate governance, which suggests that the board of directors be representative of all stakeholders that have a stack in the firm, add value, assume unique risk and possess strategic information. The COVID-19 pandemic along with the recent protests of perceived racial injustice have encourage business organizations to serve all stakeholders. The stakeholder governance paradigm suggested in this paper is supported by the WEF and is more aligned with the embedded governance framework proposed by Lubatkin, Lane, Collin and Very (2007), Lubatkin (2007), and Zahra (2007), which makes management steward of all capitals (financial, physical, reputational, social, environmental) and accountable to all stakeholders.

Exploring notions of stewardship theory, this paper examines the new stakeholder 
governance paradigm in the post-COVID era, which should be important to business organizations, their directors and executives and presents a new line of research opportunities. Stewardship theory can predict changes that international business organizations will make in modifying their corporate governance in the face of such an exogenous shock. This study examines the new normal and practices of the stakeholder governance structure built on stewardship theory to develop a conceptual stakeholder governance model including guiding principles, functions, and measures. Figure 1 presents a model of stakeholder governance consisting of stewardship theory, corporate governance principles, functions and measures and related research propositions in response to and in the aftermath of the COVID-19 pandemic. The components of this model are presented in the following sections. Specifically, the traditional functions of corporate governance are compared with new norms of stakeholder governance functions, propositions are offered, and suggestions are provided for the proper adoption of changes in corporate governance functions.

Stewardship theory by focusing on the long-term interests and wellbeing of multi-stakeholders is relevant and applicable to stakeholder governance in the post-COVID-19 era as business organization are now more concerned about safety, health and wellbeing of their employees, customers, suppliers and other stakeholders. Stewardship theory as defined by Hernandez (2012:174) is, "The extent to which an individual [management] willingly subjugates his or her personal interests to act in protection of others' [stakeholders] long-term welfare", and thus is very applicable to the new stakeholder governance paradigm presented in this paper. Two aspects of this definition, long-term orientation and protection of interests of all stakeholders, are the main drivers of management focus on safety, health and wellbeing of employees, customers, suppliers and other stakeholders in the post-COVID era, which is supported by the WEF's "Stakeholder Principles in the COVID Era" (WEF, 2020b). Stewardship theory is applicable to the new paradigm of stakeholder governance because it considers management strategic decisions and actions as stewardship behaviors that "serve a shared valued end, which provides social benefits to collective interests over the long term" Hernandez (2012: 186).

Rezaee and Fogarty (2019) define corporate governance as, "The process (journey) of managing corporate affairs and activities to create shareholder value." Larcker and Tayan $(2015$; 7) define corporate governance as, "a collection of control mechanisms that an organization adopts to prevent or dissuade potentially self-interested managers from engaging in activities detrimental to the welfare of shareholders and stakeholders." These definitions of corporate governance are modified during and in the post-COVID-19 era in ensuring that the business survives, and its continuity is secured and is sustainable and accountable to all its stakeholders. It is expected that business organizations modify their corporate governance in response to challenges presented by the COVID-19 crisis and be forced to undergo certain operational reforms as necessitated by the pandemic.

Traditionally, corporate governance functions serve as mechanisms to reduce information asymmetry between corporations and their owners. The COVID-19 pandemic is likely to have significant repercussions for how business organizations approach corporate governance. These repercussions pertain to how certain conventional governance principles relevant to the 
oversight function by the board of directors and management commitments and accountability are evolved in response to challenges imposed by the pandemic. It is expected that business organizations in order to survive and maintain their sustainability modify their business purpose of protecting interests of all stakeholders including investors, customers, suppliers, employees, and communities and adapt the new normal and stakeholder governance to ensure business continuity and prospects that benefit all stakeholders. Stakeholder governance underscores the WEF' mission statement that business organizations should "be the leaders of responsiveness and stewards of resilience," during the time of crisis (WEF 2020b).

Studying the exogenous shock in the economy caused by the COVID-19 pandemic and its effects on the stakeholder governance structure in the context of stewardship theory is important for several reasons. First, the idea of remote work and the flexible work schedule has been promoted for some time and has become a new normal during the COVID-19 pandemic and created adaptive behaviors and new norms. Second, the use of technology in corporate governance has accelerated during and in the post-COVID-19 era in enabling remote work and virtual meetings. Third, future research should address the changes in business culture, behavior, policies, and practices in response to the COVID-19 crisis and their impacts on corporate governance. Fourth, despite the devastating effects of COVID-19 pandemic on human lives, the economy and business operations, people and business organizations worldwide have demonstrated their resilience and determination to transform these challenges to opportunities by adopting a new paradigm of stakeholder governance functions to generate shared value for all stakeholders. Finally, future research can use the new stakeholder governance paradigm in the context of stewardship theory to study management decisions including strategic, operational, financing, and investment activities as well as risk assessment and the possible impacts of ongoing challenges brought on by the COVID-19 pandemic.

It is expected that the recent shift to stakeholder governance in response to the COVID-19 pandemic and recent social unrest will continue in the aftermath of the pandemic. In addition, stakeholders' interests are often in conflict and prioritizing some over others needs to be carefully considered and justified by management. The suggested stakeholder governance model and related propositions throughout the paper provide directions and opportunities for future research in corporate governance. This paper suggests that corporate governance should become more stakeholder oriented in the post-pandemic era and discusses various governance elements that should change to support this emerging stakeholder governance model. 
Proposition 1a: In the face of the COVID-19 pandemic, business organizations will tend to behave in ways that are consistent with stewardship theory.

Proposition 1b: Stewardship theory shares many core attributes of corporate governance by focusing on management strategies, decisions, and practices that promote business continuity and continuous performance improvement in response to the COVID-19 pandemic.

Proposition 2a: The stakeholder primacy concept is more likely to prevail over shareholder primacy concept in the post-COVID era.

Proposition 2b: Business organizations are more likely adopt the stakeholder governance to adjust to new normal in response to COVID-19 pandemic that demands changes in corporate culture, business environment, and business operations.

Proposition 3a: The primary oversight function of the board of directors, in the post-COVID-19 era, remains in protecting interests of multi-stakeholders by appointing competent, responsible, accountable, and ethical executives to manage the business for the benefit of all stakeholders.

Proposition 3b: The fiduciary duties of the board of directors will be extended to multi-stakeholders including shareholders, creditors, customers, suppliers, employees, government, society, and the environment with the move toward profit-with-purpose mission with ESG performance, risk, and disclosure focus.

Proposition 4a: The board of directors is likely to create a new executive position of "Chief Crisis Officer" to be responsible for addressing challenges brought on by the pandemic including managing business continuity, preventing possible disruption in supply chain, and complying with regulations.

Proposition 4b: Management with focus on survival and continuity in the post-COVID-19 era is more likely to pay attention to short-term and medium-term strategies.
Stakeholder Governance in

Response to the COVID-19

Pandemic

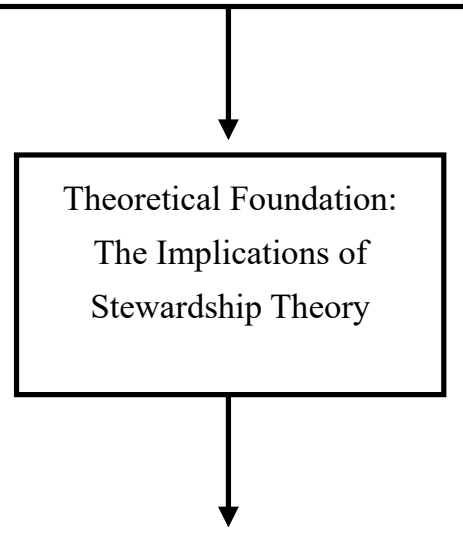

Corporate Governance Principles

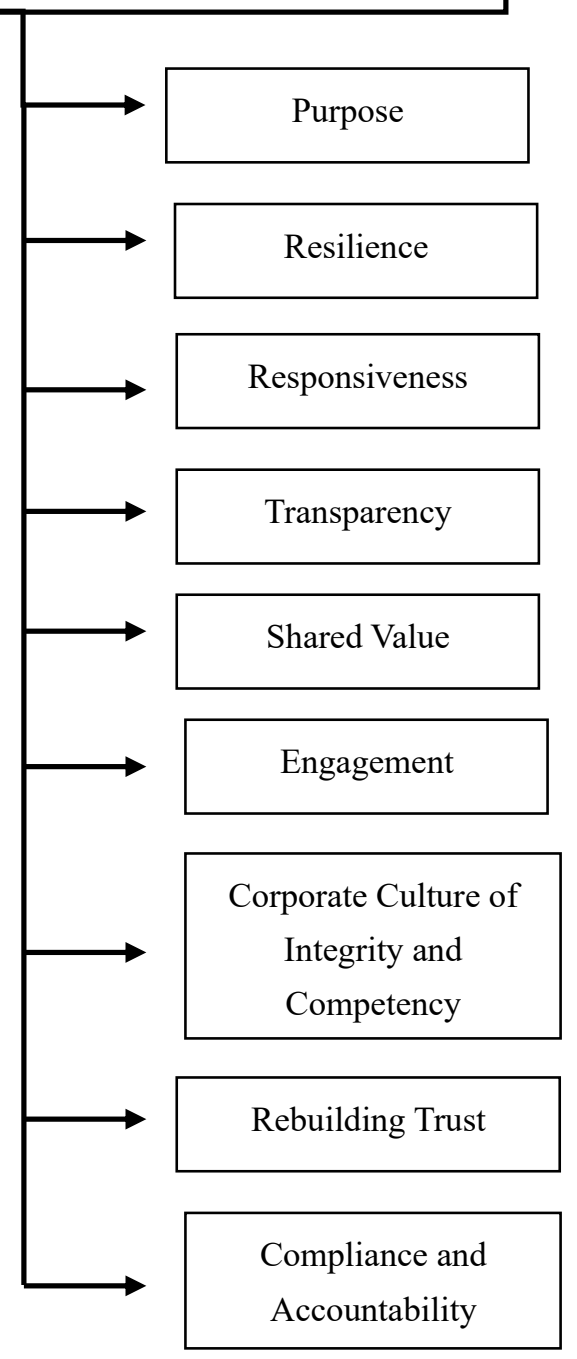


Proposition 5: Global regulators will establish more guidelines for public companies in effectively responding to challenges caused by the COVID-19 pandemic to preserve the flows of capital and credits to the capital market and economy and ensuring the continued orderly operation of the financial markets.

Proposition 6: Internal auditors will provide assurance on financial and non-financial reports for both internal and external users in the post-COVID-19 era.

Proposition 7a: Legal counsel will likely play an important role in ensuring compliance with COVID-19 emerging regulations.

Proposition 7b: Financial analysts and managers will likely provide effective advice to cope with market volatility caused by the COVID-19 pandemic and the generation of capital flows in the financial market.

Proposition 8a: The role of external auditors as protectors of investor and capital market in assuring reliability of financial reports will become more relevant and important in the post-COVID-19 era.

Proposition 8b: Auditors will modify their opinion to reflect whether going concern basis of accounting is (is not) appropriate particularly in the post-COVID-19 era.

Proposition 8c: Auditors in assessing the risks and uncertainties have caused by the pandemic will decide whether these audit issues rise to the critical matters that require adding a separate paragraph in the audit report emphasizing the matter.

Proposition 9: There will be a move away from the shareholder primacy of focusing on creation of wealth for shareholders and a move toward the stakeholder primacy of achieving shared value for all stakeholders in response to the COVID-19 pandemic.

Proposition 10: Internal and external stakeholder governance mechanisms are more relevant in the post-COVID-19 era.
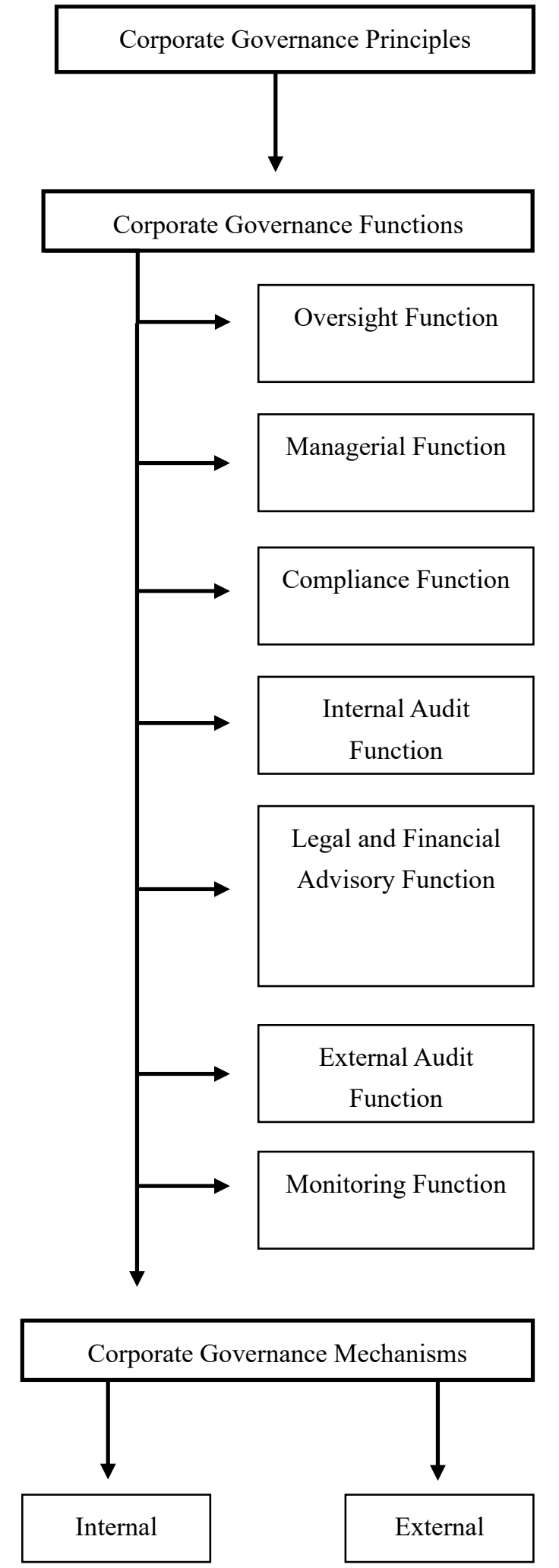

Figure 1. Stakeholder Governance Paradigm 
The remainder of this paper is structured as follows: Section II presents the stewardship theory implication whereas Section III illustrates new stakeholder governance paradigm including guiding principles, functions, and measures. Section IV provides policy, practical, education, and research implications and concludes the paper.

\section{Stewardship Theory Implication}

Management has traditionally provided stewardship of an organization's resources and its strategic decisions through the effective utilization of resources "whose motives are aligned with the objectives of their principles" (Davis et al., 1997:21) and "see greater long-term utility in other focused prosocial behavior than in self-serving, short-term opportunistic behavior" (Hernandez, 2012:172). The ongoing challenges brought on by the COVID-19 pandemic require management to effectively exercise stewardship over a broader range of financial, operational, human, social, environmental and reputational capitals to ensure continuity and prosperity in protecting safety, health and wellbeing of all stakeholders including employees, customers and suppliers. In the context of stewardship theory, stakeholders are those who have vested interests in a firm through their investments in the form of financial capital (shareholders), human capital (employees), reputational capital (customers and suppliers), social capital (society), environmental capital (the environment), and regulatory capital (government). New stakeholder governance paradigm in response to the COVID-19 pandemic should protect interests of all stakeholders, directors should assume fiduciary duties to all stakeholders and management should be the steward of all capitals as discussed in detail in the next two sections.

The COVID-19 pandemic has significant implications for individuals and organizations because it has created a new normal that affects corporate governance. Rezaee (2016) synthesizes several sustainability/governance-related theories including agency/shareholder, stakeholder, signaling/disclosure, institutional, legitimacy, and stewardship. These theories are interrelated and compatible and thus individually and collectively address different aspects of corporate governance. Stewardship theory presented in this section is more relevant to stewardship challenges brought on by the COVID-19 pandemic. In the face of the pandemic, firms will tend to behave in ways that are consistent with stewardship theory as summarized in Table 1 and further explained in this section. The new normal and standards for economic, management strategic plans and business operations and sustainability fit well with the assumptions underlying stewardship theory. The four attributes of stewardship theory including shared value creation, stakeholder perspective, business integration, and continuous improvements are relevant to the stakeholder governance paradigm in response to the COVID-19 pandemic as explained in Table 1. 
Table 1. Alignment between Stewardship Attributes and COVID-19 Challenges under the New Stakeholder Governance

\begin{tabular}{ll}
\hline Stewardship Attributes & \multicolumn{1}{c}{ COVID-19 Challenges and Stewardship Implications } \\
\hline Creation of shared & $\begin{array}{l}\text { Management as steward is responsible and accountable to protect the interests of } \\
\text { value }\end{array}$ \\
& than those that monitor and control" (Davis et al., 1997: 26). Management \\
& strategic decisions and actions as stewardship behaviors that "serve a shared \\
& valued end, which provides social benefits to collective interests over the long \\
& term" Hernandez (2012: 186). The challenges brought on by the COVID-19 \\
& pandemic demand management to protect safety, health and wellbeing of \\
& employees, customers, suppliers and other stakeholders and create shared value \\
& for all stakeholders.
\end{tabular}

\section{Stakeholder perspective}

Business Integration

\author{
Sustainability and \\ continuous \\ performance
}

Stewardship, as defined by Hernandez (2012: 174) is "the extent to which an individual [management] willingly subjugates his or her personal interests to act in protection of others' [stakeholders] long-term welfare".

Donaldson \& Preston (1995) suggest management is accountable to all stakeholders in protecting their long-term interests. Stewardship requires that management engage all stakeholders in the company's governance, strategy, performance and risk in creating shared value. In the face of the pandemic, firms will tend to behave in ways that are consistent with the stakeholder perspective of stewardship theory.

Stewardship enables the promotion of business integration from operation, investing, financing to supply chain. Hernandez (2012:122) states that stewardship theory promotes "the long-term best interests of a group ahead of personal goals that serve an individual's self-interests". Belle $(2015,5)$ states that "recent interpretations of stewardship in organizations have shifted the perspective from satisfying reporting needs to a longer-term view of recalibrating the practice of ownership and promoting an orientation towards sustainability." The COVID-19 pandemic forces management to consider business integration and continuity from supply chain to product delivery to ensure sustainability and going concern.

Stewardship requires management to engage in activities in the post-COVID-19 era to improve financial and non-financial performance in protecting interests of all stakeholders from investors to employees, suppliers, customers and communities.

Stewardship theory suggests a balance between competing interests to achieve a common good for all stakeholders (Bright and Godwin, 2010). Stewardship theory is based on structural, risk-based, and principal-agent prescriptions with a keen focus on both qualitative and quantitative performance (Davis et al., 1997) that is crucial to business continuity and survival in response to the COVID 19 pandemic. 
Stewardship theory is relevant to the new corporate governance paradigm in response to the COVID-19 pandemic in a situation where management considers the right balance between the short-term survival of the business and the long-term continuity and interests of a variety of stakeholders. The link between business, society, and the environment is complex and often tense and becomes more relevant in the post-COVID-19 era because management is now required to be a good steward of all capitals from financial to human and social. Stewardship theory helps to address COVID-19 challenges, ensure safety, health, and wellbeing of employees, customers, and suppliers as well as shared value for all stakeholders. In this context, management acts as the steward of strategic capital, financial capital, human capital, social capital, and environmental capital and acts as the active and long-term oriented steward of all stakeholders including shareholders. Stewardship theory can provide a means by which management can engage with the board of directors and other corporate gatekeepers (legal counsel financial advisors, auditors) as explained in the next section to effectively addressed all challenges brought on by the COVID-19 pandemic. As steward of business resources, management's primary role is to design and implement strategies that create shared value for all stakeholders by improving performance while addressing business challenges in managing both opportunities and risks brought on by the COVID-19 pandemic.

Stewardship theory is the most relevant theory in providing a theoretical foundation and a conceptual model for the new stakeholder governance paradigm in response to the COVID-19 pandemic. Thus, management is more likely inclined to focus on stewardship theory of protecting all capitals including financial, human, social, reputational, and environmental in response to COVID-19 pandemic, which is not adequately addressed in the existing literature. This leads to the development of the following propositions pertaining to stewardship theory and corporate governance integration.

Proposition 1a: In the face of the COVID-19 pandemic, business organizations will tend to behave in ways that are consistent with stewardship theory.

Proposition 1b: Stewardship theory shares many core attributes of corporate governance by focusing on management strategies, decisions, and practices that promote business continuity and continuous performance improvement in response to the COVID-19 pandemic.

\section{Stakeholder Governance Paradigm}

Corporate governance effectiveness has been the focus of business organizations and their stakeholders including shareholders, employees, suppliers, customers, and communities and has become more important in response to the COVID-19 pandemic. The new paradigm of stakeholder governance recognizes the importance of business survival and continuity in the short-term as well as sustainable value creation for all shareholders in the long-term as corporate strategy to deal with the pandemic. The new paradigm views corporate governance as coordination and collaboration among all corporate governance participants from shareholders to boards of directors, executives, and other stakeholders to achieve financial and nonfinancial sustainability performance in creating shared value for all stakeholders in 
the post-COVID-19 era. While the emerging new stakeholder governance paradigm may not resolve all issues and challenges brought on by the COVID-19 pandemic, it enables global business organizations to better realize their responsibility for the safety, health, and wellbeing of employees, customers, and suppliers as well as redefine their business purpose of achieving financial, social, and environmental impacts. The new stakeholder governance paradigm requires a new coherent set of guiding principles driven by shared value concept, new governance functions redefining the fiduciary duties of directors and executives to all stakeholders, and a new set of corporate governance measures that reflect new challenges and commitments triggered by the COVID-19 pandemic.

Rezaee and Fogarty (2019) identify and define the three components of corporate governance structure as principles, functions, and mechanisms that are relevant to the new stakeholder governance paradigm. Ebers and Oerlemans (2016) present other types of hybrid governance structures that could also be relevant to the business environment in the post-COVID-19 pandemic. The new stakeholder governance paradigm with its three components provides a road map for all corporate governance participants, including shareholders in being attentive in monitoring their investments, boards of directors in providing effective and engaged oversight, executives in diligently implementing short, medium, and long-term sustainable business strategies, and other corporate gatekeepers (auditors, legal counsel, financial analysts) in protecting interests of all stakeholders. These corporate governance components are generic and their relevance in the post-COVID-19 pandemic era is examined in this paper.

\subsection{Stakeholder Governance Principles}

Stakeholder governance principles provide guidelines for corporate participants from the board of directors to executives, auditors, and investors to effectively discharge their responsibility. Stakeholder governance principles are emerging and intended to provide a basic framework and foundation for an effective governance that are applicable to all types and sizes of organizations in the post-COVID-19 era. The relevant guiding principles of stakeholder governance in the post-COVID-19 pandemic are discussed in the following sections. (note 1)

\subsubsection{Purpose}

The purpose of the corporation has evolved in the past several decades as profit maximization to shareholder wealth maximization to creation of shared value for all stakeholders (Rezaee and Fogarty, 2019). The latter purpose can be achieved when corporations focus on generating desired financial returns for their shareholders while protecting interests of other stakeholders including customers, employees, suppliers, communities, society, and the environment. The economic order, stakeholder expectations, corporate culture, and business environment are changing in the post-COVID-19 era and how business organizations define their purpose and measure the achievement of their success are changing too. The COVID-19 pandemic along with social justice issues cause business organizations to address social and environmental issues beyond their traditional view of the business purpose. Changes in the purpose, mission, objectives, and strategies for business organization in response to the 
COVID-19 crisis need to be assessed and modified by focusing on the achievement of sustainable financial economic performance and nonfinancial environmental, social, and governance (ESG) sustainability performance.

Companies are now adopting the corporate mission of profit-with purpose in creating shared value for all stakeholders by shifting their goals to create shareholder value while fulfilling their social, environmental, and governance responsibilities (Rezaee and Fogarty, 2019). The statement of purpose should also define objectives, which have substantially changed in the post-COVID-19 pandemic to survival in the short-term, continuity in the medium-term, and sustainability in the long-term. The new corporate objectives should ensure: (1) workplace protection; (2) adaption of the new working conditions for employees; (3) business continuity by keeping supply chains open; (4) fair prices and customer satisfaction; (5) desired financial returns for investors; and (6) social and environmental impacts. The board of directors in collaboration with management should also design strategies to achieve new objectives by designing business continuity plans, deliberate decisions, and crisis management.

\subsubsection{Resilience}

Resilience reflects the corporate ability to cope with undesirable events and maintain its continuity and sustainability. A resilient corporate governance is sustainable and enduring in the sense that it will easily recover and recuperate from crisis. The COVID-19 pandemic was a shock to the economy, business operations, and social norms. One possible impediment to the traditional corporate governance structure caused by the pandemic is the challenges and their detrimental effects on the corporate flexibility, openness, and responsiveness. The corporate resilience in coping with challenges brought on by the COVID-19 pandemic and adjusting operation, procedures, and processes to effectively deal with these challenges is crucial in its continuity as a going concern and its long-term sustainability. It is expected that the board of directors exercise oversight of business resiliency during and in the aftermath of the COVID-19 pandemic.

\subsubsection{Responsiveness}

The company's timely and appropriate responses to the concerns and challenges caused by the COVID-19 pandemic are important considerations by business organizations and their board of directors and executives. Proper responses to requests by shareholders and other stakeholders including investors, customers, employees, auditors, suppliers, and communities need to be considered and made. Effective corporate governance is responsive to reasonable requests from all corporate governance participants, emerging issues, and changes in regulations dealing with social distancing, remote working, and environmental among other issues. Business organizations are facing the challenges of rebuilding and recovery processes in addressing workplace safety culture, wealth inequity, testing, quarantining, workplace contact tracing, work interruption contingency plans and contagion-based operational pauses.

\subsubsection{Transparency}

Transparency in fairly and clearly disclosing both favorable and unfavorable financial and non-financial information to all corporate stakeholders is crucial during and in the aftermath 
of the COVID-19 pandemic. Transparent communication should be easy to understand by all corporate governance participants. This is an important principle of effective stakeholder governance and has become more essential in informing how the organization is planning to address all challenges caused by the COVID-19 pandemic. One important element of the well-balanced and fair disclosure is the judgment and decisions made by the board of directors and management in response to ongoing challenges of the pandemic. Corporations should be transparent regarding changes that are made to their operation, financing and investment decisions and activities in response to the pandemic.

\subsubsection{Shared Value}

Stakeholder governance should promote shared value creation and enable and incentivize seven governance functions described in the next section to add value to the organization's sustainability and enduring performance. Shared value creation for all stakeholders can be promoted within the wealth-maximization framework in pursuing the goal of profit-with-purpose for corporations. Corporations can create a right balance between the wealth-maximization for shareholders under the shareholder primacy concept while achieving the welfare-maximization for all stakeholders (e.g., safety, health and wellbeing of employees, suppliers, and customers) under the stakeholder primacy concept. The concept of impact investing of focusing on the importance and relevance of corporate investment strategies in creating desired returns on investment for shareholders and providing positive social and environment impacts is gaining acceptance and is more relevant in the post-COVID-19 pandemic.

\subsubsection{Engagement}

Engagement of all stakeholders in the organization activities is crucial in the post-COVID-19 pandemic to eliminate surprises and undesirable outcomes. The engagement creates incentives to add value and derives performance and results. Stakeholder engagement rebuilds confidence and encourages deliberate calm and proper decisions. Proactive and transparent engagement with all stakeholders in the post-COVID-19 pandemic is crucial to the business continuity and sustainability. The pandemic challenges all stakeholders to be engaged in corporate activities and governance. The Business Roundtable (BRT) on August 19, 2019 announced the adoption of a new Statement on the Purpose of a Corporation, signed by 181 well-known, high-powered chief executive officers (CEOs), which requires engaging and protecting interests of all stakeholders in contributing to an economy that serves all Americans (BRT, 2019).

\subsubsection{Corporate Culture of Integrity and Competency}

A firm's corporate culture of integrity and competency to deal effectively and ethically with challenges brought on by the COVID-19 pandemic plays a key part in setting the standards and enforcing stakeholder governance. Corporate culture plays a role of "social control" and new normal as individuals within the organization and in society are under pressure to act a certain way such as social distancing, remote working, virtual meetings among other new normal and standards. The board of directors has a fiduciary responsibility to oversee 
corporate culture that generates positive impacts on operational performance, business reputation, talent development, and employee morale. As corporations consider reopening their business operations, culture issues are extending to safety, health, and wellbeing of their employees, customers and suppliers during and in the aftermath of the pandemic. Business organizations should express that there will be no tolerance of violations of the new normal and standards. It is essential that the board of directors sets an appropriate tone at the top in overseeing that the organization is dedicated to ethics and compliance with new normal and standards for business practices in the post-COVID-19 era. Having a better understanding of the organization's culture and core values can enable organizations to effectively address challenges caused by the pandemic and create shared value for all stakeholders.

\subsubsection{Rebuilding Trust}

In response to recent financial crises and stock price volatility caused by the COVID-19 pandemic, it is not uncommon for investors to lose confidence in a firm's going-concern and sustainability. Business organizations and their board of directors and executives can rebuild trust by providing relevant, reliable, and transparent financial and non-financial information to all stakeholders, particularly those who have been negatively affected by the COVID-19 pandemic such as investors, employees, customers, and suppliers. To rebuild trust, directors must establish proper communication with all stakeholders in understanding their concerns, ideas, and feedback in effectively coping with the pandemic. The board of directors in collaboration with management should establish strategic plans, policies, and procedures to respond to concerns, issues, and insight of stakeholders to rebuild trust.

\subsubsection{Compliance and Accountability}

Compliance with all applicable laws, rules, regulations, standards, new normal, and best practices in the post-COVID-19 era is crucial to the survival and sustainability of business organizations. Accountability reflects the relationship between organization's objectives, decisions, actions, and performance and develops the cornerstone of stakeholder governance by continuously monitoring decisions, actions, and performance. The main drivers of accountability are the acceptance of responsibility, ethical decision making, and transparency. Corporate governance should foster accountability by developing strategic priorities. All corporate governance participants should be held accountable and responsible for their decisions, actions, and performance.

All the above discussed stakeholder governance guiding principles are relevant in response to the COVID-19 pandemic in focusing on stakeholder primacy concept with profit-with purpose mission of creating shared value for all stakeholder, particularly assuring business continuity and securing safety, health and wellbeing of employees, customers, suppliers and other stakeholders. The following propositions can be made regarding stakeholder governance guiding principles in response to the Covid-19 pandemic.

Proposition 2a: The stakeholder primacy concept is more likely to prevail over shareholder primacy concept in the post-COVID era.

Proposition 2b: Business organizations are more likely adopt the stakeholder governance to 
adjust to new normal in response to COVID-19 pandemic that demands changes in corporate culture, business environment, and business operations.

\subsection{Stakeholder Governance Functions}

Stakeholder governance reflects corporate culture, accountability, and leadership in response to emerging challenges. In response to COVID-19 pandemic, business organizations are experiencing ongoing challenges that affect their governance structure and the way they manage their business under the new normal of stakeholder governance. Rezaee and Fogarty (2019) present the seven corporate governance functions as oversight, managerial, compliance, internal audit, legal and financial advisory, external auditing, and monitoring.(note 2) This section examines the modifications in these seven traditional functions of corporate governance in the post-COVID-19 pandemic. Table 2 contrasts the traditional corporate governance functions with the new stakeholder governance functions relevant in the post-COVID-19 era.

Table 2. Comparison of Functions of the Traditional Corporate Governance and the New Stakeholder Governance (pre-and post-COVID-19 Pandemic)

\begin{tabular}{|c|c|c|}
\hline Functions & $\begin{array}{l}\text { Traditional Corporate Governance } \\
\text { Functions (Pre-Pandemic) }\end{array}$ & $\begin{array}{l}\text { New Stakeholder Governance Functions } \\
\text { (Post-Pandemic }\end{array}$ \\
\hline Oversight & $\begin{array}{l}\text { Representative of shareholders to protect } \\
\text { their interests. } \\
\text { Shareholder-primacy focus. } \\
\text { Oversight of the organization affairs in } \\
\text { creating shareholder value. } \\
\text { Pursue the mission of profit maximization } \\
\text { and shareholder wealth creation. } \\
\text { Strategy-driven oversight activities. } \\
\text { Primary focus on the achievement of } \\
\text { financial performance. }\end{array}$ & $\begin{array}{l}\text { Representative of all stakeholders in protecting } \\
\text { shared value. } \\
\text { Stakeholder-primacy focus } \\
\text { Oversight of the organization affairs in creating } \\
\text { shared value for all stakeholders. } \\
\text { Pursue the mission of profit-with-purpose in } \\
\text { creating shared value for all stakeholders. } \\
\text { Purpose/mission -driven oversight activities. } \\
\text { Focus on achievement of financial and } \\
\text { non-financial ESG performance. }\end{array}$ \\
\hline Managerial & $\begin{array}{l}\text { Focus on short-term performance. } \\
\text { Achievement of profit maximization and } \\
\text { shareholder wealth creation. } \\
\text { Executives (CEO and CFO) certification } \\
\text { of financial statement and internal controls } \\
\text { over financial reporting. } \\
\text { Financial risk assessment and } \\
\text { management. } \\
\text { Steward of financial Capital. }\end{array}$ & $\begin{array}{l}\text { Focus on business continuity and sustainable } \\
\text { performance. } \\
\text { Achievement of profit-with-purpose in creating } \\
\text { shared value for all stakeholders. } \\
\text { Executives (CEO and CFO) certification of both } \\
\text { financial and non-financial reports and internal } \\
\text { controls over financial reporting. } \\
\text { Financial and non-financial risk assessment and } \\
\text { management. } \\
\text { Steward of financial, human, social, reputational, } \\
\text { and environmental capitals. }\end{array}$ \\
\hline
\end{tabular}


Compliance Rebuild public trust and investor confidence in public financial information and capital markets.

Regulations promoting the shareholder primacy concept.

Financial regulations.

$\begin{array}{ll}\text { Internal } & \text { Focus on financial audits. } \\ \text { Audit } & \text { Consulting services for management. } \\ & \text { Assurance services on financial and } \\ & \text { internal controls, }\end{array}$

Legal and Legal and financial advisory services for Advisory management.

Manual and electronic legal and financial evidence.

$\begin{array}{ll}\text { External } & \text { Focus on financial audits. } \\ \text { Audit } & \text { Risk-based audit approach. } \\ & \text { Financial and internal control audit. } \\ & \text { Emphasis of Matters. } \\ & \text { Less going concern issues. } \\ \text { Monitoring } & \text { Shareholder primacy and centric. } \\ & \text { Shareholder monitoring. } \\ & \text { Shareholder accountability. } \\ & \text { Shareholder democracy. } \\ & \text { In person proxy advisers }\end{array}$

Rebuild public trust and investor confidence in public financial and non-financial information and capital markets.

Regulations promoting the stakeholder primacy concept.

Financial and non-financial regulations pertaining to social, environmental, and human capitals.

Focus on financial and nonfinancial audits.

Consulting services for all corporate gatekeepers.

Assurance opinion on financial and nonfinancial information and internal controls.

Legal and financial advisory services for all corporate gatekeepers.

Electronic legal and financial evidence.

Focus on financial and nonfinancial audits.

Risk and compliance-based audit approach.

Financial and internal control audits and assurance services on nonfinancial information.

Critical Audit Matters.

More going concern issues.

Stakeholder primacy and centric.

Stakeholder monitoring.

Stakeholder accountability and transparency.

Stakeholder democracy.

Virtual proxy advisers.

\subsubsection{Oversight Function}

As the representative of shareholders, the board of directors is ultimately responsible for business affairs and has a fiduciary duty to initiate and oversee managerial strategies, decisions, and actions taken to achieve corporate objectives. The primary oversight function of the board of directors remains in protecting interests of multi-stakeholders during this challenging time and appointing competent, responsible, accountable, and ethical executives to manage the business for the benefit of all stakeholders. In times of crisis, the company's board of directors faces challenges and heightened scrutiny of their decisions and actions by stakeholders, especially shareholders. While, directors are typically protected under the business judgment rule for making good faith efforts and decision to navigate the COVID-19 pandemic, they should be mindful of emerging regulatory rules and health guidelines regarding safety, health and wellbeing of employees, customers, suppliers, and other affected 
stakeholders.

In the post-COVID-19 pandemic era, it is expected that the board of directors engage more proactively in the oversight function in setting strategic priorities in dealing with global economic and political uncertainties and challenges caused by the pandemic, and the potential risk of substantial interruptions in business operations and supply chain. The fiduciary duties of the board of directors are expected to be extended to multi-stakeholders including shareholders, creditors, customers, suppliers, employees, government, society, and the environment with the move toward profit-with-purpose mission. The oversight function of the board of directors and its board committees including audit, compensation, nomination and compliance committees becomes more relevant in the aftermath of the COVID-19 pandemic to ensure that the corporate compliance system is adequately designed and effectively implemented. The importance of board committees in stakeholder governance in overseeing financial reporting processes, executive compensation, risk assessment as underscores by Kolev, Wangrow, Barker and Schepker (2019) has become more relevant in response to the COVID-19 pandemic.

The COVID-19 pandemic has introduced complexity to the fundamental roles and responsibilities of directors who must oversee the managerial function under the emerging risks and uncertainties particularly those associated with assessment and management of human capital risks. In the aftermath of the pandemic protecting interests of all stakeholders from shareholders to employees, customers, and communities become priorities of the board of directors. Many boards pay attention to "protect our people" by redesigning their human capital resources policies and procedures. The board of directors should work with management to modify corporate culture and business environment and behavior in developing and implementing a "reopening plan". There are many uncertainties regarding the achievement of long-term strategic plans considering the COVID-19 pandemic. Thus, the board of directors should now focus more on short and medium outcomes and have their eyes on the long-term impacts of the pandemic. While stakeholders, particularly investors are more interested in long-term sustainability and earnings growth, ensuring that their company can survive the pandemic's shock and able to operate in the short-to medium-term should be an important consideration for all stakeholders including shareholders.

The possible modifications in the oversight function of the board of directors discussed above lead to the following research propositions:

Proposition 3a: The primary oversight function of the board of directors, in the post-COVID-19 era, remains in protecting interests of multi-stakeholders by appointing competent, responsible, accountable, and ethical executives to manage the business for the benefit of all stakeholders.

Proposition 3b: The fiduciary duties of the board of directors will be extended to multi-stakeholders including shareholders, creditors, customers, suppliers, employees, government, society, and the environment with the move toward profit-with-purpose mission with ESG performance, risk, and disclosure focus. 


\subsubsection{Managerial Function}

The managerial function of stakeholder governance is delegated to and assumed by the management team appointed by the board of directors. Management's primary responsibilities are to achieve operational efficiency and effectiveness, comply with all applicable laws, rules, regulations and standards, proper assessment of risk, and fair and true disclosure of both financial and non-financial information. The immediate impact of the COVID-19 pandemic is substantial loss of jobs worldwide and the unemployment rate has reached all-time high of about 14.7 percent in the United States in April 2020 (Bureau of Labor Statistics, BLS, 2020). For example, about 11 percent of the Russell 3000 have announced drastic cuts for their executives' base salary in response to the business shutdown caused by the COVID-19 pandemic with the majority of these pay cuts in hard-hit business industries including hospitality, retail, health care, and technology (The Conference Board, 2020).

The COVID-19 pandemic has brought unique risks to business operations, practices, and performance that need to be considered by the board of directors and assessed by management. To effectively address these emerging and growing business challenges and risks, the board of directors may form a new executive position of "Chief COVID Officer" to be responsible for: (1) assessing and managing the COVID-19-related risks; (2) ensuring compliance with all applicable rules, regulations, and standards to protect safety and well-being of all stakeholders, particularly customers, suppliers, and employees; (3) managing business continuity; (4) preventing possible disruption in supply chain; and (5) complying with all the growing government guidelines and regulations (Haas et al., 2020). The designated Chief COVID Officer should have all qualifications, knowledge, and experience to deal with all emerging challenges and risks associated with the COVID-19 pandemic (Haas et al., 2020). The entire management team and particularly, the finance function and finance teams led by the CFO, are facing significant challenges caused by the COVID-19 pandemic. Among these challenges for the CFO during and in the post-COVID-19 pandemic are protection of employees in terms of safety and health, changing the work environment enabling remote working, human capital risk assessment, supply chain disruption, and financial budget modification in providing adequate cash and liquidity. Possible changes in the managerial function lead to the following research propositions:

Proposition 4a: The board of directors is likely to create a new executive position of "Chief Crisis Officer" to be responsible for addressing challenges brought on by the pandemic including managing business continuity, preventing possible disruption in supply chain, and complying with regulations.

Proposition 4b: Management with focus on survival and continuity in the post-COVID-19 era is more likely to pay attention to short-term and medium-term strategies.

\subsubsection{Compliance Function}

The compliance function of stakeholder governance creates a regulatory framework for business organizations in effectively operating within and in compliance with the regulatory framework in achieving sustainable performance. In response to the COVID-19 pandemic, 
policymakers, regulators, and standard-setters should be both reactive and proactive in establishing and enforcing cost-effective, efficient, and scalable rules and regulations to address many emerging challenges. Regulations should establish a framework within which business organizations can achieve sustainable performance while following COVID-related rules. Regulators worldwide should provide guidelines to all market participants from investors to exchanges, public companies, broker dealers, investment companies, credit rating agencies, public accounting firms, and central clearing parties to assist them in proper and effective implementation of business continuity measures including virtual business, investor meetings, and remote work environments.

The Coronavirus Aid, Relief, and Economic Security (CARES) Act of 2020 provides an estimated \$2.2 trillion to fight the COVID-19 pandemic with the intent to stimulate the US economy (CARES Act, 2020). The CARES Act creates the Paycheck Protection Program (PPP) and initially devotes $\$ 349$ billion to provide certain small businesses with liquidity to continue and support their operations during the COVID-19 pandemic. Furthermore, an additional $\$ 310$ billion was later authorized for the PPP. As of this writing, US Congress has passed three bills of COVID-19 stimulus packages intended to mitigate the economic impact of the COVID-19 pandemic and put liquidity into the economy. Changes in the compliance function lead to the following research proposition:

Proposition 5: Global regulators will establish more guidelines for public companies in effectively responding to challenges caused by the COVID-19 pandemic to preserve the flows of capital and credits to the capital market and economy and ensuring the continued orderly operation of the financial markets.

\subsubsection{Internal Audit Function}

The internal audit function of stakeholder governance is conducted by internal auditors. Internal auditors have traditionally performed both assurance and consulting services for business organizations in the areas of operational efficiency, governance processes, risk management, internal controls, financial reporting. Assurance reports provided by internal auditors are currently intended for internal use by management and could be extended to other external users in response to the COVID-19 pandemic in providing assurance on financial and non-financial reports. Internal auditors are well positioned and trained to provide numerous assurance services in addressing challenges presented by the COVID-19 crisis. Internal auditors are in a unique position to work with the board of directors and management in assessing changes brought on by the COVID-19 pandemic to their organizations, design appropriate policies, and processes to address these changes, educate employees about these policies and procedures, and ensure compliance with relevant new normal, standards, policies, and procedures brought on by the COVID-19 pandemic.

The Committee of Sponsoring Organizations of the Treadway Commission (COSO) issued its new guidance on risk appetite to assess how the risk appetite can be used in decision-making (COSO, 2020). The COSO guidance can assist internal auditors in working with management to design and implement strategy and objectives to cope with challenges of maintaining sustainability performance and business continuity in the post-COVID-19 pandemic. Changes 
in internal audit function in the post-COVID-19 era lead to the following research proposition:

Proposition 6: Internal auditors will provide assurance on financial and non-financial reports for both internal and external users in the post-COVID-19 era.

\subsubsection{Legal and Financial Advisory Function}

The legal and financial advisory function of stakeholder governance is performed by professional financial advisors, the internal, and external legal counsel. Legal counsel provides legal advice and assists the company in complying with applicable laws, regulations, rules, and other legal requirements. In response to the COVID-19 pandemic, legal counsel plays more important role in ensuring compliance with emerging regulations. Financial analysts can provide more effective advice to cope with market volatility caused by the COVID-19 pandemic.

Corporate legal counsel should evaluate regulatory risks associated with corporate communications with all stakeholders during times of corporate crisis, particularly those disclosures relevant to health, safety and wellbeing of employees, suppliers, and customers in the post-COVID-19 era. Corporate board, executives and legal counsel often consider what is too little or too much to disclose in a time of crisis and often the problem is about what a company does not disclose rather than what it does disclose. Thus, in a time of crisis such as the COVID-19 pandemic, the board of directors and executives in consultation with the legal counsel properly and effectively, accurately and transparently communicate with all stakeholders all important matters, particularly those associated with the company's products and services. The corporate legal counsel is in a unique position and well-situated to inform and advise the company's board of directors, its board committees, especially the compliance committee and executives regarding the potential compliance and regulatory risks during and in the post-COVID-19 pandemic. The company's general counsel should review fiduciary duty standards of the board of directors to ensure they follow the new "statement of purpose" and the profit-with-purpose mission debated in the recent years. Sidebar 5 compares legal and financial advisory function in the pre-and-post COVID-19 pandemic. The changes in the legal and financial advisory function of corporate governance lead to the following research propositions:

Proposition 7a: Legal counsel will likely play an important role in ensuring compliance with COVID-19 emerging regulations.

Proposition 7b: Financial analysts and managers will likely provide effective advice to cope with market volatility caused by the COVID-19 pandemic and the generation of capital flows in the financial market.

\subsubsection{External Audit Function}

The external audit function of stakeholder governance is intended to lend more credibility to the published financial statements of business organizations. This function conducted by external auditors for publicly listed companies. Auditors provide professional opinions on the presentation of the company's financial statements in conformity with generally accepted 
accounting principles (GAAP) and the effectiveness of internal control over financial reporting (ICFR). The primary objective of the external audit remains the same in response to the COVID-19, however the audit methodology is expected to be more electronic and electronic audit evidence be collected virtually. The economic and business challenges brought on by the COVID-19 pandemic can create more opportunities for external auditors to assist their clients to address the challenges.

External auditors' responsibility has traditionally been regarded as protecting investors in receiving misleading and materially misstated financial statement by assuring the accuracy, completeness, and reliability of financial information. In the post-COVID-19 era, the role of external auditors as protectors of investor and capital market becomes more relevant and important. To improve audit quality, external auditors comply with guidelines provided by the American Institute of Certified Public Accountants (AICPA) COVID-19 Auditing and Accounting Resources relevant to planning a remote audit, risk assessment and response, and communications and reporting (AICPA, 2020). Similar pandemic guidelines are issued by the International Auditing and Assurance Standards Board (IAASB) in its staff audit practice alert (IAASB, 2020). External auditors should communicate with their clients through social media (emails, phone calls, webinars, virtual meetings, Skype, Zoom) in providing auditing, assurance, and attestation services. Many clients are concerned with their health, safety, and health of their employees, suppliers, and customers, their business continuity and going concern and thus external auditors should consider all these challenges and concerns when planning financial audits.

The changes in the external audit function in the post-COVID-19 era lead to the following research propositions:

Proposition 8a: The role of external auditors as protectors of investor and capital market in assuring reliability of financial reports will become more relevant and important in the post-COVID-19 era.

Proposition 8b: Auditors will modify their opinion to reflect whether going concern basis of accounting is (is not) appropriate particularly in the post-COVID-19 era.

Proposition 8c: Auditors in assessing the risks and uncertainties have caused by the pandemic will decide whether these audit issues rise to the critical matters that require adding a separate paragraph in the audit report emphasizing the matter.

\subsubsection{Monitoring Function}

The monitoring function of stakeholder governance is the primary responsibility of stakeholders including shareholders and can be achieved through stakeholders protecting their interest and the direct engagement of shareholders in looking after their investment. Shareholders play an important role in monitoring public companies to ensure their rights and interests are protected. Corporate sustainability has become an economic and strategic imperative with potential to create shared value for all stakeholders. The COVID-19 pandemic has affected all organizations regardless of their types and sizes worldwide. Particularly, corporations are significantly challenged as their investors have been hit hard and they are 
facing unprecedented and heightened scrutiny by their investors.

Public companies in the United States have traditionally operated under the corporate model of "shareholder primacy" that makes the board of directors' judiciary responsible only to shareholders in protecting their interests. Under the shareholder primacy system, the primary purpose of a corporation is to generate returns for shareholders, and thus corporate activities are managed toward creating shareholder value. This shareholder primacy system is also known as the U.S corporate governance model and is being criticized for focusing on generating short-term profits for shareholders while compromising long-term sustainability performance that creates shared value for all stakeholders and promotes innovation, growth, social, and environmental impacts. The stakeholder primacy system, which is better known as the European corporate governance model makes the board of directors' fiduciary responsible to protecting interests of all stakeholders including shareholders, creditors, employees, customers, suppliers, society, and the environment.

Recently released the Business Roundtable Statement on the Purpose of a Corporation to, "create value for all stakeholders, recommends the move away from the shareholder primacy concept toward the stakeholder primacy concept that promotes sustainability of creating shared value for all stakeholders (BRT, 2019). Corporate purpose and stakeholder considerations have gained recognition in the business community worldwide. The stakeholder primacy challenges companies to put stakeholders at the heart of a company's purpose. A shift in corporate purpose from shareholder primacy to stakeholder primacy, reinforced by the US Business Roundtable's Statement on the Purpose of a Corporation. This focus, combined with public pressure for CEOs to engage on social and political topics (e.g., human capital, diversity, immigration, gun control, gender pay equity) along with challenges brought on by the COVID-19 pandemic encourage corporate America to advance towards business sustainability. Harrison, Phillips, and Freeman (2020) present research opportunities presented by the BRT statement of purpose in areas of "firm boundaries, the nature of value creation systems, and theory regarding the destruction of stakeholder value" that are relevant in the post-COVID-19 era.

Changes in the monitoring function of corporate governance caused by the pandemic lead to the following research proposition:

Proposition 9: There will be a move away from the shareholder primacy of focusing on creation of wealth for shareholders and a move toward the stakeholder primacy of achieving shared value for all stakeholders in response to the COVID-19 pandemic.

\subsection{Corporate Governance Mechanisms/Measures}

The stakeholder governance structure is shaped by internal and external governance mechanisms, as well as policy interventions through regulations. Both internal and external corporate governance mechanisms (board independence, board committees, SOX Act of 2002) of the company have evolved over time and are expected to be significantly modified in the post-COVID-19 era. Internal mechanisms are aimed at managing, directing, and monitoring corporate activities to create shared value for all stakeholders. Examples of internal governance 
mechanisms are the board of directors and related board committees (audit, compensation, and nominating committees), management team lead by the CEO, internal controls (operational, financial, and compliance), and the internal audit function. External governance mechanisms are designed to monitor the company's activities, affairs, and performance to ensure the company and its directors and officers work for the best benefit of all stakeholders. Examples of external mechanisms are laws passed by Congress (SOX Act of 2002; CARES Act of 2020) regulations developed by the SEC, FSB, and IOSCO relevant to public companies, the capital market, the labor market, and the market for corporate control, as well as court decisions, shareholder proposals, and best practices of investor activists. Recent COVID-19 crisis indicates that a combination of both internal and external mechanisms is needed to protect interests of all stakeholders. The effectiveness and relevance of both internal and external corporate governance mechanisms depend on the cost-benefit, efficiency, scalability, and proactiveness.

Stakeholder governance mechanisms discussed in this section should address these challenges and minimize their negative impacts. Internal mechanisms include a vigilant board of directors in overseeing new purpose, mission, objectives, and strategies in response to the COVID-19 pandemic, executives' determinations to implement proper strategies to minimize the negative impacts and ensure continuity of operations as well as effective internal controls to achieve the stated objectives. External mechanisms are applicable laws, regulations, rules, and standards, which are intended to reopen the economy and businesses to ensure sustainability and economic and earnings growth in the post-COVID-19 pandemic. Oh, Cheng, and Kim (2018) conclude that multiple corporate governance mechanisms act as substitute to promote CSR and their findings should be confirmed in the post-COVID-19 era. Stakeholder governance measure propositions is:

Proposition 10: Internal and external stakeholder governance mechanisms are more relevant in the post-COVID-19 era.

\section{Conclusion}

The COVID-19 pandemic has caused many challenges worldwide including a substantial shrinkage in the global economy, a significant earnings loss for business organizations, and unprecedented changes in organizational behavior including unemployment, disruption to business practices and supply chain, high safety and health risk for employees and a significant stock price volatility. This manuscript examines the exogenous shock in the economy and organization behavior caused by the COVID-19 pandemic and applies stewardship theory in determining the possible changes that business organization have made with respect to their governance in the face of such an exogenous shock. The pandemic has triggered changes in the oversight function by the board of directors, the managerial function by executives and the monitory function by corporate gatekeepers in response to the COVID-19 pandemic.

International business organizations should modify their corporate governance to ensure that 
they turn these challenges to opportunities by mitigating the negative impacts on all stakeholders. The effectiveness of the traditional corporate governance has been challenged by the COVID-19 pandemic and thus a new stakeholder governance is emerging to focus of the protection for all stakeholders. The primary objective of this study is to examine the stakeholder governance in response to and in the aftermath of the COVID-19 Pandemic. Specifically, it attempts to: (1) synthesize the existing literature on corporate governance and the COVID_19 pandemic; (2) examine the COVID-19 prevailing challenges and suggest ways to turn these challenges into business opportunities; and (3) address lessons learned from the crisis and the provide suggestions for possible modifications to corporate governance structure including guiding principles, measures and functions. Corporate governance effectiveness has been the focus of business organizations and their stakeholders including shareholders, employees, suppliers, customers, and communities and become more important in the aftermath of the COVID-19 pandemic. The stakeholder governance recognizes the importance of business survival and continuity in the short-term as well as sustainable value creation in the long-term as corporate strategy to deal with the pandemic. The stakeholder governance views an organization as a collation of participants from shareholders to boards of directors, executives, and other stakeholders to achieve financial and nonfinancial sustainability performance in creating shared value for all stakeholders. It provides a road map for all corporate governance participants, including shareholders, to be attentive in monitoring their investment, boards of directors in providing effective and engaged oversight, executives in diligently implementing long-term and sustainable business strategies, and other corporate gatekeepers (auditors, legal counsel, financial analysts) in protecting interests of all stakeholders.

Business organizations should understand the emerging move towards the stakeholder governance with focus on sustainability factors of performance, risk and disclosure and integration of these factors into managerial policies, decisions and processes to protect their stakeholders, avoid a prolonged detrimental economic effect, assist those who are impacted and secure future earnings growth and economic prosperity. It is expected that the pandemic is likely to accelerate the adoption of new measures and practices of stakeholder governance including the adoption new standing board committee or executive position in charge of COVID-19 pandemic. The primary purpose of this paper is to examine the new stakeholder governance paradigm and investigate changes in organizational behavior and the traditional corporate governance principles, functions, and measures in response to the COVID-19 pandemic.

This paper attempts to provide an early insight into the COVID-19 crisis and their impact on organizational behavior including corporate governance norms, measures, and practices and offer research propositions. Despite the devastating effects of COVID-19 pandemic on human lives and economic well-being and associated challenges, people and business organizations worldwide have demonstrated their resilience and determination to change these challenges to opportunities of improving governance effectiveness and adopting a new norm for stakeholder governance functions. Thus, the importance and relevance of stakeholder governance functions in the post-COVID-19 crisis need to be examined in 
determining the roles, responsibilities, and accountability of all corporate governance gatekeepers from the board of directors to executives, auditors, regulators, legal counsel, financial analysts, and investors.

The COVID-19 pandemic has underscored the move toward stakeholder-oriented governance. Modifications in corporate governance principles, functions, and mechanisms highlighted in this study assist business organizations to effectively adapt to these changes and challenges brought on by the COVID-19 pandemic. The suggested stakeholder governance principles, functions and mechanisms presented in this paper should assist all governance participants from the board of directors to management, auditors, legal counsel, stakeholders to address, and take actions to mitigate critical risks facing the company during and in response to the COVID-19 pandemic. These risks are but not limited to financial and operational challenges, business and supply chain disruption, continuity plans, cybersecurity and privacy issues, safety, health and wellbeing of employees, customers and suppliers including to those associated with employee leave and remote work policies and other regulatory, legal and compliance risks.

This study provides policy, practical, education, and research implications in the post-COVID-19 era and furthers our understanding of possible aspects and features of the pandemic and research opportunities to investigate their effects. The COVID-19 pandemic is a new phenomenon that creates many research opportunities. Scholars can conduct a survey of professional and corporate governance experts to obtain insight about the possible effects of the pandemic on organizational behavior including stakeholder governance and its principles, functions, and measures. Vigorous and robust scholarly and empirical studies need to be conducted in examining short-and-long-term economic impacts and recovery and economic plans to achieve growth, and prosperity for the nation. A stream of research can investigate the "statement of purpose" for business organizations and changes in business environment including redesigning business operations and processes, supply chain, remote working, flexible work time, and virtual approach in conducting business in the post-COVID-19 era. Finally, research propositions offered throughout the paper provide guidelines and opportunities for researchers to conduct experimental, analytical, and empirical studies in examining the ongoing challenges and effects of the COVID-19 pandemic on many aspects of business organizations and their governance.

This study contributes to the conceptual organizational behavior and corporate governance literature by developing theoretical framework and propositions that can be empirically tested. Examination of the effects of COVID-19 on corporate governance functions is important for several reasons. First, the idea of remote work and the flexible work schedule has been promoted for some time and has become a new normal/standard during the COVID-19 pandemic. Second, the use of technology in corporate governance has been developing in recent years and has accelerated in the post-COVID-19 era with significant impacts on the finance function. Third, future research can use insights from experts to advance research regarding the changes in business culture, behavior, policies, and practices in the aftermath of the COVID-19 crisis. Finally, this paper is intended to provide an early insight into the COVID-19 crisis and their impact on corporate governance norms, measures, and practices. 
Despite the devastating effects of COVID-19 pandemic on human lives and economic well-being and associated challenges, people and business organizations worldwide have demonstrated their resilience and determination to change these challenges to opportunities of improving corporate governance effectiveness and adopting a new normal for corporate governance functions and particularly the finance function.

As with any conceptual paper, there are several limitations of this manuscript that deserve more attention. First, this paper synthesizes the existing literature and provides insight into the modifications in corporate governance in response to the COVID-19 pandemic and by nature is a descriptive study. Thus, suggested propositions should be tested in an empirical setting. Second, this paper has demonstrated that there is a need for a shift toward stakeholder governance in response to the COVID-19 pandemic. The discussion of whether this shift will likely continue after the current crisis is over and management still pays attention to all stakeholders, not only to shareholders need to be further examined. Third, there should be further discuss of how conflicts among stakeholders will be resolved by management who acts as good steward. Prior research shows that stakeholders' interests are often in conflict and prioritizing some over others needs to be carefully justified based on some criteria. Fourth, there are significant differences among firms and countries as to how much and if they adopt stakeholder governance in response to the current economic crisis. It is possible that firms in some countries are more likely to embrace stakeholder governance and management behaves more like stewards than those in other countries. Finally, in some countries, directors already must consider stakeholders' interests when they discharge their duties based on corporate governance code or company law. While the suggested stakeholder governance model and its components and propositions may not resolve all issues and challenges facing corporations today including cybersecurity and related cyberattacks, technology disruption, social media, political instability, and globalization, it enables business organizations to better realize their purpose with both financial and social and environmental impacts as well as their responsibility to all stakeholders today and in the post-COVID-19 pandemic era.

\section{Acknowledgements}

This manuscript benefits from the invaluable comments and suggestions of Jay Thibodeau and Darryl Poole.

\section{References}

American Institute of Certified Public Accountants (AICPA).2020. Coronavirus (COVID-19) Auditing and Accounting Resources. Retrieved from https://www.aicpa.org/eaq/covid19

Brammer, S., Branicki, L., \& Linnenluecke, M. (2020). COVID-19, Societalization and the Future of Business in Society. Academy of Management Perspectives, In-Press, June 2020. 
Barnett, M, L., Henrigues, I., \& Husted, B. W. (2020). Beyond Good Intentions: Designing CSR Initiatives for Greater Social Impact. Journal of Management, 46(6), 937-964.

Bebchuk, L A., \& Tallarita, R. (2020). The Illusory Promise of Stakeholder Governance (February 26, 2020). Forthcoming, Cornell Law Review, December 2020. Retrieved from https://ssrn.com/abstract=3544978 or http://dx.doi.org/10.2139/ssrn.3544978

Belle, S. M. (2015). Knowledge Stewardship as an Ethos-Driven Approach to Business Ethics. Journal of Business Ethics, 1-9.

Bright, D. S., \& Godwin, L. N. (2010). Encouraging social innovation in global organizations: Integrating planned and emergent approaches. Journal of Asia-Pacific Business, 11(3), 179-196.

Bureau of Labor Statistics (BLS). (2020). The Employment Situation (April 2020). Retrieved from https://www.bls.gov/news.release/pdf/empsit.pdf

Business Roundtable (BRT). (2019). Statement on the purpose of the corporation. Retrieved from

https://opportunity.businessroundtable.org/wpcontent/uploads/2019/08/BusinessRoundta bleStatement-on-the-Purpose-of-a-Corporation-with-Signatures.pdf

Davis, J. H., Schoorman, F. D., \& Donaldson, L. (1997). Toward a stewardship theory of management. Academy of Management Review, 22(1), 20-47.

Donaldson, T., \& Preston, L. E. (1995). The stakeholder theory of the corporation: Concepts, evidence, and implications. Academy of Management Review, 20(1), 65-91.

Ebers, M., \& Oerlemans, L. (2016). The variety of Governance Structures beyong Market and Hierarchy. Journal of Management, 42(6) (September 2016), 1491-1529.

Haas, S., \& Goolsby, A. (2020). Hunton Andrews Kurth LLP, A Special Committee to Oversee the Corporation's Response to the Pandemic. Retrieved from 22 April, 2020 https://corpgov.law.harvard.edu/2020/04/21/a-special-committee-to-oversee-the-corpora tions-response-to-the-pandemic/

Hahn, T., Preuss, L., Pinkse, J., \& Figge, F. (2014, October). Cognitive Frames in Corporate Sustainability: Managerial Sensemaking with Paradoxical and Business Case Frames. Academy of Management Review, 39(4), 463-487.

Harrison, J. S., Phillips, R. A., \& Freeman, R.E. (2020). On the 2019 Business Roundtable Statement on the Purpose of a Corporation. Journal of Management. In Press.

Hernandez, M. (2012). Toward an understanding of the psychology of stewardship. Academy of Management Review 2012, 37(2), 172-193.

Kaufman, A., \& Englander, E. (2005). Ateam production model of corporate governance. Academy of Management Perspectives, 19(3),9-22.

Kolev, K. D., Wangrow, D. B., Barker III, V. L., \& Schepker, D. J. (2019). Board 
Committees in Corporate Governance: A Cross-Disciplinary Review and Agenda for the Future. Journal of Management Studies, 56(6) (September 2019), 1138-1154.

Larcker, D., \& Tayan, B. (2015). Corporate governance matters: A closer look at organizational choices and their consequences. Pearson Education.

Lubatkin, M., Lane, P. J., Collin, S., \& Very, P. (2007). An embeddedness framing of governance and opportunism: Towards a cross-nationally accommodating theory of agency. Journal of Organizational Behavior, 28, 43-58.

Lubatkin, M. (2007). One more time: What is a realistic theory of corporate governance? Journal of Organizational Behavior, 28, 59-67.

Mayer, C. (2019). Prosperity: Better Business Makes the Greater Good. Oxford University Press, Oxford, United Kingdom, January 1, 2019.

Mohrman, A., OToole, J., \& Lawler, E. E. (2015). Corporate Stewardship: achieving sustainability effectiveness. Greenleaf Publishing Limited, UK.

Oh W, Y., Chang, Y. K., \& Kim, T. Y. (2018). Complementary or Substitute Effects? Corporate Governance Mechanisms and Corporate Social Responsibility. Journal of Management, 44(7) (September 2018), 2716-2739.

Rezaee, Z. (2016). Business sustainability research: A theoretical and integrated perspective. Journal of Accounting Literature, 36, 48-64.

Rezaee, Z., \& Fogarty, T. (2019). Business Sustainability, Corporate Governance, and Organizational Ethics. John Wiley \&Sons Inc, New Jersey, United States.

Sarbanes-Oxley Act. (2002). The Public Company Accounting Reform and Investor Protection Act. Retrieved from http://www.whitehouse.gov/infocus/corporateresponsibility.

Texas State Board of Public Accountancy (TSBPA). (2020). Rule 511.57 Qualified Accounting Courses: Texas Administrative Code. Retrieved 12 March, 2020 from https://texreg.sos.state.tx.us/public/readtac\$ext.TacPage?sl=R\&app=9\&p_dir=\&p_rloc= $\& p \_t$ loc $=\& p \_p l o c=\& p g=1 \& p \_t a c=\& \mathrm{ti}=22 \& \mathrm{pt}=22 \& \mathrm{ch}=511 \& \mathrm{rl}=57$

The Committee of Sponsoring Organizations of the Treadway Commission (COSO). (2020). Risk Appetite-Critical to Success. Retrieved May 2020 from https://www.coso.org/Documents/COSO-Guidance-Risk-Appetite-Critical-to-Success.p df

The Conference Board. (2020). Executive and Director Compensation Reductions in the COVID-19 Era. Retrieved April 2020 from https://conferenceboard.esgauge.org/covid-19/payreductions

The Coronavirus Aid, Relief, and Economic Security (CARES) Act. (2020). 116 Congress, $2^{\text {nd }}$ Session, S.3548. Retrieved 19 March, 2020 from https://www.congress.gov/116/bills/s3548/BILLS-116s3548is.pdf 


\section{Macrothink}

Journal of Corporate Governance Research ISSN 1948-4658 2020, Vol. 4, No. 1

The International Auditing and Assurance Standards Board (IAASB). (2020). Staff Audit Practice Alert: Auditor Reporting in the Current Evolving Environment due to COVID-19. Retrieved May 2020 from https://www.ifac.org/system/files/publications/files/Staff-Alert-

Auditor-ReportinFinal.pdf?utm_source $=$ IFAC+Main+List\&utm_campaign $=87173 \mathrm{fe}$ 1a0-EMAIL_CAMPAIGN_2018

The World Economic Forum (WEF). (2020a). Integrated Corporate Governance: A Practical Guide to Stakeholder Capitalism for Boards of Directors. White Paper. Retrieved June 2020 from http://www3.weforum.org/docs/WEF_Integrated_Corporate_Governance_2020.pdf

The World Economic Forum (WEF). (2020). World Economic Forum Pledges to Stand by Stakeholders in the COVID-19 Era. Retrieved 24 April, 2020 from https://www.briefinggovernance.com/2020/04/world-economic-forum-pledges-to-standby-stakeholders-in-the-covid-19-era/

Zahra, S. A. (2007). An embeddedness framing of governance and opportunism: Toward a cross-nationally accommodating theory of agency-critique and extension. Journal of Organizational Behavior, 28, 69-73.

\section{Notes}

Note 1. These principles are not all inclusive but there are most relevant in response to the COVID-19 pandemic and thus the most comprehensive set of corporate governance principles can be found in the governance literature.

Note 2. These seven corporate governance functions are comprehensive and go beyond the traditional power-sharing functions of shareholders, the board of directors and management often described in the corporate governance literature.

\section{Copyright Disclaimer}

Copyright for this article is retained by the author(s), with first publication rights granted to the journal.

This is an open-access article distributed under the terms and conditions of the Creative Commons Attribution license (http://creativecommons.org/licenses/by/3.0/). 